\title{
Coronavirus Infections in the Central Nervous System and Respiratory Tract Show Distinct Features in Hospitalized Children
}

\author{
Yuanyuan $\mathrm{Li}^{\mathrm{d}}$ Haipeng Li ${ }^{\mathrm{b}}$ Ruyan Fan ${ }^{\mathrm{a}}$ Bo Wen ${ }^{\mathrm{a}}$ Jian Zhang ${ }^{\mathrm{a}}$ \\ Xiaoying Cao ${ }^{c}$ Chengwu Wang ${ }^{a}$ Zhanyi Songa Shuochi Li $^{a}$ Xiaojie $\mathrm{Li}^{\mathrm{a}}$ \\ Xinjun Lv ${ }^{\mathrm{e}}$ Xiaowang Qu ${ }^{\mathrm{a}}$ Renbin Huang ${ }^{\mathrm{b}}$ Wenpei Liu $^{\mathrm{a}}$ \\ aTranslational Medicine Institute and b Department of Neurology, The First People's Hospital of Chenzhou, and \\ 'Department of Infectious Disease, The Second People's Hospital of Chenzhou, Chenzhou, d Department of \\ Neurology, The Third People's Hospital of Yancheng, Yancheng, and 'National Institute of Viral Disease Control and \\ Prevention, China CDC, Beijing, China
}

\section{Key Words}

Coronavirus · Respiratory tract · Central nervous system ·

Cytokine

\begin{abstract}
Background/Aims: Coronavirus (CoV) infections induce respiratory tract illnesses and central nervous system (CNS) diseases. We aimed to explore the cytokine expression profiles in hospitalized children with CoV-CNS and CoV-respiratory tract infections. Methods: A total of 183 and 236 hospitalized children with acute encephalitis-like syndrome and respiratory tract infection, respectively, were screened for anti-CoV IgM antibodies. The expression profiles of multiple cytokines were determined in CoV-positive patients. Results: Anti-CoV lgM antibodies were detected in 22/183 (12.02\%) and 26/236 (11.02\%) patients with acute encephalitis-like syndrome and respiratory tract infection, respectively. Cytokine analysis revealed that the level of serum granulocyte colony-stimulating factor (G-CSF) was significantly higher in both CoV-CNS and CoV-respiratory tract infection compared with healthy controls. Additionally, the serum level of granulocyte macrophage colony-stimulating factor (GM-CSF) was significantly higher in
\end{abstract}

CoV-CNS infection than in CoV-respiratory tract infection. In patients with CoV-CNS infection, the levels of IL-6, IL-8, MCP-1, and GM-CSF were significantly higher in their cerebrospinal fluid samples than in matched serum samples. Conclusion: To the best of our knowledge, this is the first report showing a high incidence of CoV infection in hospitalized children, especially with CNS illness. The characteristic cytokine expression profiles in CoV infection indicate the importance of host immune response in disease progression.

๑ 2017 S. Karger AG, Basel

\section{Introduction}

Coronavirus $(\mathrm{CoV})$ is an enveloped virus with a large positive-sense, single-stranded RNA genome [1-3] belonging to the Coronaviridae family [4]. Human pathogenic CoVs include $\mathrm{HCoV}-229 \mathrm{E}, \mathrm{HCoV}-\mathrm{OC} 43, \mathrm{HCoV}$ HKU1, HCoV-NL63, severe acute respiratory syndrome $\mathrm{CoV}$ (SARS-CoV), and Middle East respiratory syndrome

Yuanyuan Li and Haipeng Li contributed equally to this article.

\section{KARGER}

E-Mail karger@karger.com www.karger.com/int
(C) 2017 S. Karger AG, Basel

0300-5526/17/0593-0163\$39.50/0
Wenpei Liu or Renbin Huang

No. 102 Luojiajing, Beihu District

Chenzhou, Hunan 423000 (China)

E-Mail wenpeiliu_2008@hotmail.com or huang_renbin@163.com 
CoV (MERS-CoV) [5-7]. Human pathogenic CoVs are associated with a wide range of respiratory illnesses, including common colds, pneumonia, and bronchiolitis [7]. Additionally, several studies have described that CoVs are associated with CNS diseases such as acute disseminated encephalomyelitis and multiple sclerosis [8-10]. Respiratory tract infection contributes to high morbidity and mortality with a worldwide disease burden estimated at 112,900,000 disability-adjusted life years and 3.5 million deaths [11]. Furthermore, the mortality of viral encephalitis ranges from 4.6 to $29 \%$ and nearly $50 \%$ of survivors are at a high risk of developing neurological disorders [12].

The effect of $\mathrm{CoV}$ infection is influenced by various factors, including environmental factors, genetic factors, and immune-mediated process [10]. Cytokines are widely recognized as important mediators of inflammatory response [13]. For instance, IL-6 is a proinflammatory cytokine that induces the terminal differentiation of proliferating B cells to plasma cells, stimulates antibody secretion, and enhances T-lymphocyte responses in secondary lymphoid organs [14]. Further, IL-8 is a C-X-C chemokine that functions as a potent chemotactic agent for polymorphonuclear cells and lymphocytes [15] and is associated with blood-brain barrier breakdown [16]. MCP-1 is a C-C chemokine that can initiate the transmigration of monocytes across the blood-brain barrier [16]. Several studies have shown that IL-6, IL-8, and MCP-1 contribute to severe respiratory disease progression in SARS infections [17-19]. Granulocyte colony-stimulating factor (G-CSF) expression is often induced during $\mathrm{CoV}$ infections, resulting in systemic (i.e., in the plasma) and local increases in inflammatory fluids either in mice or humans, such as patients with rheumatoid arthritis and severe respiratory syncytial virus infection [20-22]. Recent studies have suggested that granulocyte macrophage colony-stimulating factor (GM-CSF) also has proinflammatory functions and plays critical roles in the development of autoimmune and inflammatory diseases such as autoimmune encephalomyelitis [23, 24].

In this study, we conducted a comprehensive analysis to investigate clinical features and cytokine profiles in hospitalized children diagnosed with either central nervous system (CNS) or respiratory tract infection of $\mathrm{CoV}$.

\section{Materials and Methods}

\section{Patients and Samples}

The inclusion criteria in this study for the diagnosis of clinically suspected acute encephalitic patients were modified according to the previous study as follows [25]: (1) age <16 years and (2) hos- pitalized with at least 2 of the following encephalitis-like symptoms or signs with a duration of illness of $<7$ days: fever $\geq 38^{\circ} \mathrm{C}$ (axillary), headache, neck stiffness, convulsion, altered levels of consciousness $>24 \mathrm{~h}$, and focal neurological signs. A total of 183 hospitalized children with clinically suspected acute encephalitis and 236 children with acute respiratory tract infection were enrolled from May 2014 to April 2015 at the Children's Hospital of Chenzhou (Hunan Province, China). On the day of admission, blood samples were collected from patients with respiratory tract infection and paired samples of blood and cerebrospinal fluid were collected from patients with clinically suspected acute encephalitis. Then, to exclude bacteria, fungus, or Mycobacterium tuberculosis infection from subsequent data analysis, $1 \mathrm{ml}$ of cerebrospinal fluid specimens were subjected to microbiological investigations. Control blood samples were collected from age-matched children $(n=26)$ without infection who underwent surgery. The patients' clinical data were collected for further analysis. The study's protocol was approved by the Ethics Committee of the Hospital for Human Studies and written consent forms were obtained from the parents of the participants. The course of illness was defined in this study as the period from the onset of symptoms to the disappearance of symptoms.

\section{CoV Detection}

All CoVs infections were identified by detection of anti-CoV IgM (Boyan, Shanghai) by ELISA according to the manufacturer's instructions. In brief, $10 \mu \mathrm{L}$ serum/cerebrospinal fluid samples mixed with $40 \mu \mathrm{L}$ sample diluents were incubated with pan-CoV antigen-coated 96-well plates, and anti-human IgM antibodies labeled with peroxidase were then analyzed by an automatic microplate reader.

\section{Cytokine Measurement}

Expression levels of multiple cytokines (IL-1 $\beta$, IL-2, IL-4, IL-5, IL-6, IL-7, IL-8, IL-10, IL-12p70, IL-13, IL-17A, G-CSF, GM-CSF, IFN- $\gamma$, MCP-1, MIP- $1 \beta$, and TNF- $\alpha$ ) were measured in the serum samples of patients with respiratory tract infection, serum samples of healthy controls, and matched paired serum and cerebrospinal fluid samples of patients with viral encephalitis-like syndrome by the Bio-Plex Assay (Bio-Rad, USA) following the manufacturer's instructions.

\section{Statistical Analyses}

Differences between continuous variables were evaluated by the Student $t$ test or Mann-Whitney U test, while differences between categorical variables were evaluated by the $\chi^{2}$ test. Statistical analyses were carried out by the SPSS 18.0 software. The results were considered significant for 2 -sided $p$ values of $\leq 0.05$.

\section{Results}

Clinical Characteristics of Hospitalized Children with CoV Infection in the CNS and Respiratory Tract

Among 183 hospitalized children with clinically suspected acute encephalitis, $22(12.02 \%)$ were identified with $\mathrm{CoV}$ infection. Vomiting (36.4\%), headache $(45.5 \%)$, and fever $(81.8 \%)$ were the most common symptoms of these patients (Table 1). Among CoV-en- 
Table 1. Clinical characteristics of hospitalized children with central nervous system coronavirus infection

\begin{tabular}{lc}
\hline Patient characteristics & Values $(n=22)$ \\
\hline Demographics & \\
Male & $18(81.8)$ \\
Age, months & $36.00(0.83-72.00)$ \\
Rural & $17(77.3)$ \\
Course of illness ${ }^{\text {a }}$, day & $14.50(10.00-22.25)$ \\
Symptom & \\
Peak body temperature, ${ }^{\circ} \mathrm{C}$ & $38.50(37.60-39.10)$ \\
History of fever & $18(81.8)$ \\
Headache & $10(45.5)$ \\
Vomiting & $8(36.4)$ \\
Diarrhoea & $1(4.5)$ \\
Seizure & $5(22.7)$ \\
Altered mental status & $0(0)$ \\
Sign & \\
Neck stiffness & $7(31.8)$ \\
Kering sign & $2(9.1)$ \\
Brudzinski sign & $1(4.5)$ \\
Babinski sign & $2(9.1)$ \\
Image (normal/abnormal) & \\
MRI or CT $(n=16)$ & $8 / 8$ \\
EEG $(n=3)$ & $3 / 0$ \\
Laboratory findings & $10(45.5)$ \\
Pleocytosis & $18(81.9)$ \\
Normal CSF glucose & $8(36.4)$ \\
Elevated CSF protein & $22(100)$ \\
Outcome at discharge & $0(0)$ \\
Full recovery & \\
Mild neurological sequelae & \\
\hline & \\
\hline &
\end{tabular}

Values are presented as $n(\%)$ or medians (range). ${ }^{\text {a }}$ Course of illness is from the onset of symptoms to the disappearance of symptoms.

cephalitis patients, there were 18 males and 4 females with an average age of 36 months. Most of these patients $(77.3 \%)$ lived in rural areas. Sixteen patients underwent MRI or CT, of which 8 (50\%) showed abnormal imaging accompanied with corresponding neurological defects. Among these 8 patients, 2 (25\%), including 1 with CT and 1 with MRI, showed abnormity located in the temporal lobe accompanied with seizures; 2 patients (25\%) with MRI showed abnormity located in the periventricular region accompanied with headaches; and 4 patients (50\%), including 1 patient with CT and 3 patients with MRI, showed abnormity located in the basal ganglia and thalamus accompanied with fever and/or vomiting. In this study, cerebrospinal fluid was analyzed for all patients with $\mathrm{CoV}$-associated encephalitis. Ten patients $(45.5 \%)$ presented with cerebrospinal fluid pleocytosis,
Table 2. Clinical characteristics of hospitalized children with respiratory tract coronavirus infection

\begin{tabular}{|c|c|}
\hline Patient characteristics & Values $(n=26)$ \\
\hline \multicolumn{2}{|l|}{ Demographics } \\
\hline Male & $20(76.9)$ \\
\hline Age, month (range) & $12.00(7.75-60.00)$ \\
\hline Rural & $15(57.7)$ \\
\hline Course of illness ${ }^{\mathrm{a}}$, day & $7.00(5.00-8.00)$ \\
\hline \multicolumn{2}{|l|}{ Symptom } \\
\hline Peak body temperature, ${ }^{\circ} \mathrm{C}$ & $37.30(36.88-39.40)$ \\
\hline History of fever & $13(50.0)$ \\
\hline Cough & $23(88.5)$ \\
\hline Wheeze & $13(50.0)$ \\
\hline Short of breath & $1(3.8)$ \\
\hline Produce sputum & $8(30.8)$ \\
\hline Vomiting & $0(0)$ \\
\hline Diarrhea & $1(3.8)$ \\
\hline \multicolumn{2}{|l|}{ Radiography } \\
\hline Interstitial infiltrates & $7(26.9)$ \\
\hline Alveolar infiltrates & $12(46.2)$ \\
\hline Normal & $7(26.9)$ \\
\hline \multicolumn{2}{|l|}{ Treatment } \\
\hline Inhalation of pulmicort respules & $22(84.6)$ \\
\hline Oxygen therapy & $1(3.8)$ \\
\hline Mechanical ventilation & $1(3.8)$ \\
\hline Fiberoptic bronchoscopy alveolar & \\
\hline lavage & $7(26.9)$ \\
\hline \multicolumn{2}{|l|}{ Outcome at discharge } \\
\hline Full recovery & $22(84.6)$ \\
\hline Deterioration & $4(15.4)$ \\
\hline
\end{tabular}

Values are presented as $n(\%)$ or medians (range). ${ }^{\text {a }}$ Course of illness is from the onset of symptom to the disappearance of symptom.
$18(81.9 \%)$ showed normal cerebrospinal fluid glucose, and $8(36.4 \%)$ had elevated cerebrospinal fluid protein levels. Three of the 22 patients with $\mathrm{CoV}$-associated encephalitis underwent EEG, and all the results were normal (Table 1).

Among the 236 hospitalized children with acute respiratory tract symptoms, 26 (11.02\%) were identified as having $\mathrm{CoV}$ infection. The main symptoms were coughing (88.5\%), wheezing (50\%), and fever (50\%) (Table 2). There were 20 males and 6 females with an average age of 12 months. Also, most of these patients (57.7\%) lived in rural areas, and 22 patients $(84.6 \%)$ received treatment with Pulmicort Respules (inhalation). All the patients with respiratory tract infection had undergone a chest Xray: $7(26.9 \%)$ showed interstitial infiltrates, which included 3 sole interstitial infiltrates and 4 bilateral intersti- 
Fig. 1. Peripheral blood cell counts of lymphocytes (a), eosinophils (b), neutrophils (c), and monocytes (d) among patients with coronavirus infection of the central nervous system (CoV-CNS, $n=22$ ), patients with coronavirus infection of the respiratory tract (CoV-respiratory tract, $n=$ $26)$, and healthy controls $(n=26)$. Cell counts are expressed as $10^{9}$ cells/L. Data are plotted as medians with the 10th-90th percentile ranges. The Student $t$ test or MannWhitney $\mathrm{U}$ test was performed. $p$ values were derived from a two-tailed test; $* \leq$ 0.05 .
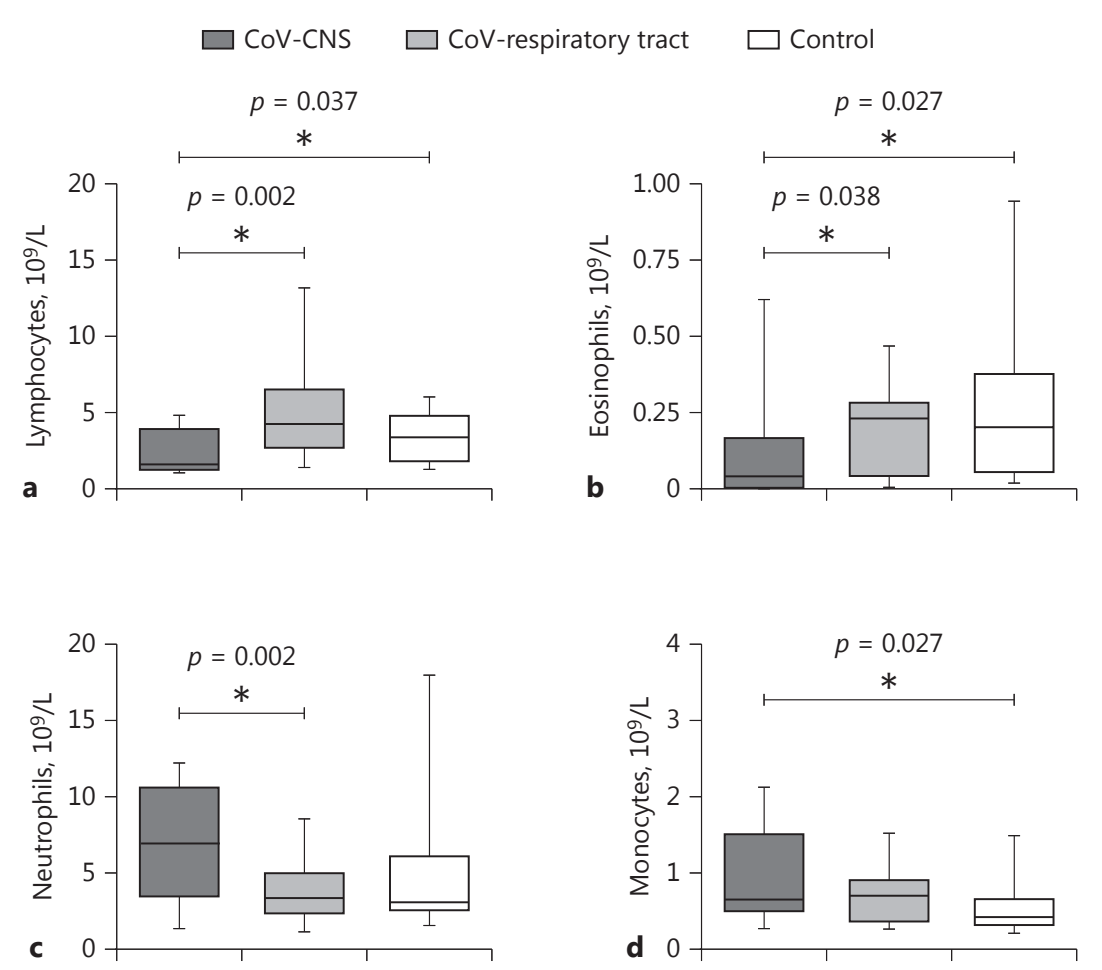

tial infiltrates; 12 (46.2\%) had alveolar infiltrates; and 7 (26.9\%) had a normal chest X-ray finding (Table 2).

\section{CoV Infection Changes Peripheral Blood Cell Count}

To further explore the difference between CoV-CNS and $\mathrm{CoV}$-respiratory tract infections, the peripheral blood cell count was analyzed in both infections. Our results show that lymphocyte and eosinophil counts were significantly lower in patients with CoV-CNS infection than in patients with $\mathrm{CoV}$-respiratory tract infection and healthy controls (Fig. 1a, b). In contrast, the neutrophil cell count was significantly lower in patients with $\mathrm{CoV}$ respiratory tract infection than in patients with $\mathrm{CoV}$ CNS infection (Fig. 1c). The monocyte count was significantly higher in patients with $\mathrm{CoV}$-CNS infection than in healthy controls (Fig. 1d).

Cytokine Expression by CoV Infection in the CNS and Respiratory Tract

To further characterize host immune response in $\mathrm{CoV}$-CNS and CoV-respiratory tract infections, a cyto- kine expression profile was determined using serum and/ or matched cerebrospinal fluid samples. This analysis revealed that the serum level of G-CSF was not significantly different between patients with $\mathrm{CoV}$-CNS and $\mathrm{CoV}$ respiratory tract infections, but it was significantly higher in both of these patient groups than in healthy controls (Fig. 2a). The serum level of GM-CSF was significantly higher in patients with CoV-CNS infection than in patients with $\mathrm{CoV}$-respiratory tract infection and healthy controls (Fig. 2b). Other cytokines showed similar expression profiles for patients with $\mathrm{CoV}$ infections in the CNS and respiratory tract as well as for healthy controls (data not shown).

Additionally, an analysis of the cytokine expression profile in matched-paired serum/cerebrospinal fluid samples of $\mathrm{CoV}-\mathrm{CNS}$ patients showed that expression levels of GM-CSF, IL-6, IL-8, and MCP-1 were significantly higher in cerebrospinal fluid than in the serum (Fig. 3a-d). Other cytokines also showed similar expression profiles in matched cerebrospinal fluid and serum samples (data not shown). 
Fig. 2. Expression levels of serum G-CSF (a) and GM-CSF (b) among patients with coronavirus infection of the central nervous system (CoV-CNS, $n=22$ ), patients with coronavirus infection of the respiratory tract (CoV-respiratory tract, $n=26)$, and healthy controls $(n=26)$. Data are expressed as medians with the 10-90th percentile ranges. The Student $t$ test or MannWhitney $\mathrm{U}$ test was performed. $p$ values were derived from a two-tailed test; ${ }^{*} p \leq$ 0.05 .

Fig. 3. Expression levels of GM-CSF (a), IL-6 (b), IL-8 (c), and MCP-1 (d) levels in matched serum (PLA) and cerebrospinal fluid (CSF) from patients with coronavirus infection $(\mathrm{CoV})$ of the central nervous system $(n=17)$. Data are expressed as medians with the 10-90th percentile ranges. Student's $t$ tests or Mann-Whitney U tests were performed. $p$ values were derived from a two-tailed test; ${ }^{*} p \leq 0.05,{ }^{* *} p \leq$ 0.001 .
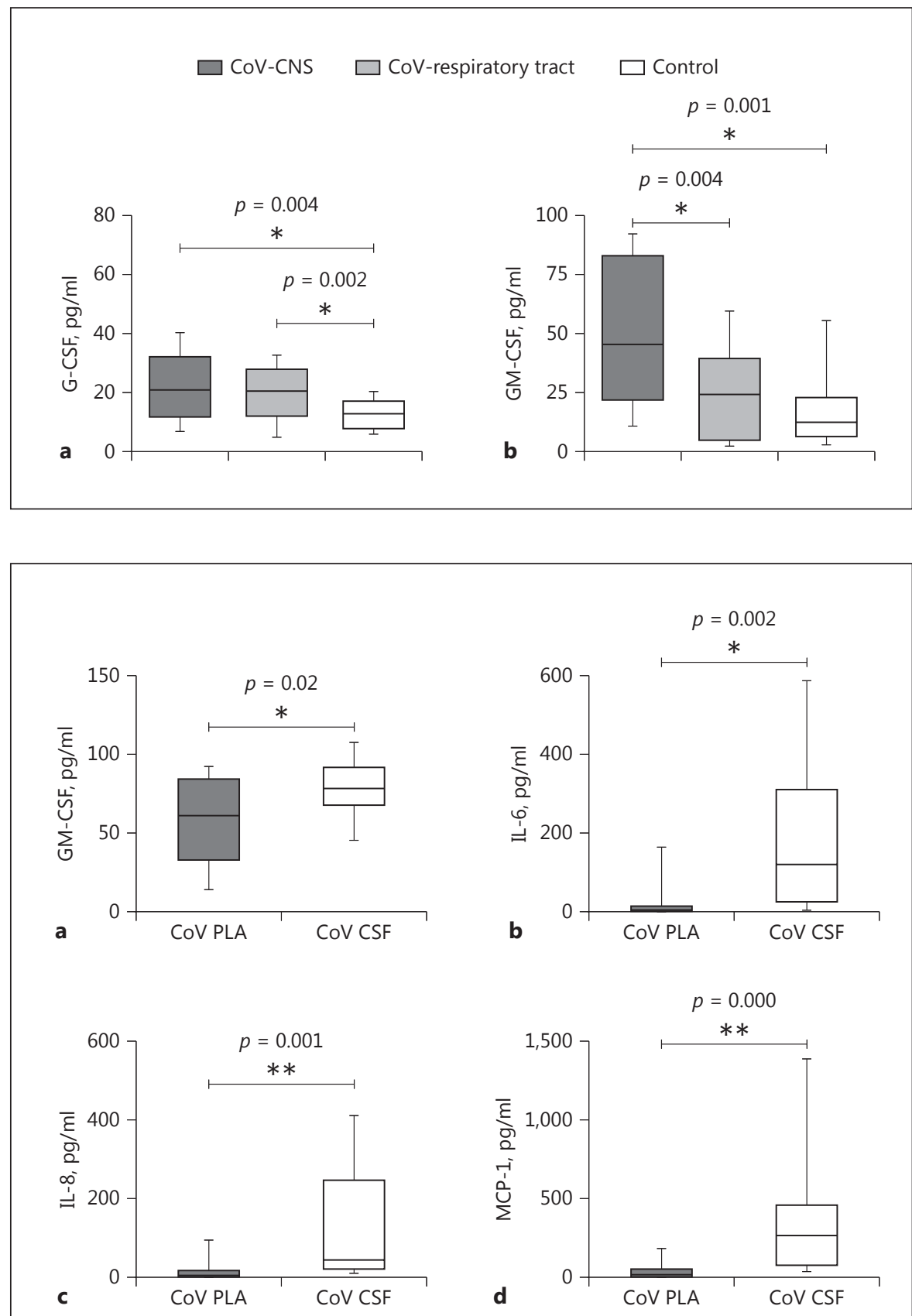

\section{Discussion}

$\mathrm{CoV}$ infection was observed in $12.02 \%$ of hospitalized children with CNS infection and $11.02 \%$ of hospitalized children with acute respiratory tract infection. While the incidence of $\mathrm{CoV}$ infection in children with acute respiratory tract infection has been previously illustrated [1], to our knowledge this is the first report showing the high incidence of $\mathrm{CoV}$ infection in hospitalized children with CNS infection. Since there was no significant difference in the age of patients with CoV-CNS infection, CoV-respiratory tract infection, and healthy controls, the difference in immune blood cell counts between CNS and respiratory tract infection could not be attributed to the difference in patient age, but rather to the difference in the nature of $\mathrm{CoV}$ tropism. 
We observed a significant increase in the serum G-CSF level in patients with either CoV-CNS or CoV-respiratory tract infections. G-CSF is one of the key regulators of granulocytosis, which plays a central role in stimulating the proliferation of granulocytic precursors, enhances their terminal differentiation, and stimulates their release from the bone marrow into the peripheral blood [20]. In addition, GM-CSF stimulates stem cells to produce granulocytes (neutrophils, eosinophils, and basophils) and monocytes [26]. Our results showed that (1) CoV-CNS infection induces a high level of GM-CSF either in serum or cerebrospinal fluid, and (2) peripheral cell counts of neutrophil cells and monocytes were significantly higher in patients with $\mathrm{CoV}$-CNS infection than in patients with $\mathrm{CoV}$-respiratory tract infection and healthy controls. These findings may suggest that GM-CSF plays an important role in controlling CNS infection through inducing neutrophils and monocyte proliferation and/or accumulation in the infection site [27]. To our knowledge, GMCSF can promote leukocyte chemotaxis and adhesion, upregulate the antimicrobial functions of neutrophils as a secondary immune response to the virus, and provide protection against viral encephalitis [28-30]. In addition, the increased neutrophils can afford protection against viral infection. Several reports have implied direct roles for them in the targeting of infected cells or virions: neutrophils can adhere to infected cells after complement activation and phagocytose antibody-coated virions [31, 32]. However, this issue needs to be further investigated through in vitro studies examining the production of GM-CSF from blood cells isolated from patients with $\mathrm{CoV}-\mathrm{CNS}$.

Although high serum levels of IL-6, IL-8, and MCP-1 in SARS- and MERS-infected patients have been illustrated [17-19], we did not find a significant increase in the serum level of these cytokines among our patient cohort. However, we found that IL-6, IL-8, and MCP-1 were significantly accumulated in the cerebrospinal fluid of patients with $\mathrm{CoV}-\mathrm{CNS}$ infection. IL-6 has neurotrophic and neuroprotective effects and can increase blood-brain barrier permeability [33]. A high level of IL-6 leads to progressive neurological disorders with neurodegeneration and cognitive decline [34]. The higher level of cerebrospinal fluid IL-8 seen in this study is consistent with the fact that CNS viral infection might induce proliferation of microglia and astrocytes, resulting in the release of IL-8 [35]. An experimental Japanese encephalitis mouse model demonstrated that IL-8 plays an important role in inflammatory responses involving injury to the brain [36]. MCP-1 is a C-C chemokine that can initiate

the transmigration of monocytes across the blood-brain barrier and recruit inflammatory cells into the CNS, thereby facilitating the entry of virus-infected cells, as well as amplifying the inflammatory response, which damage the brain $[16,37]$. These accumulated cytokines may also contribute to immune damage in the CNS of patients with $\mathrm{CoV}$ infection similar to that observed in other viral encephalitis.

Even though there are important outcomes of this study, there are also several limitations: (1) the sample size was small and (2) we collected samples only at admission. Future studies with a larger sample size analyzing blood and cerebrospinal fluid samples collected at multiple time points are needed to monitor the kinetics of cytokine expression profile during the course of illness.

In conclusion, this study suggests that $\mathrm{CoV}$ infection of the CNS is common and multiple cytokine expression profiles are involved in the initial host's immune response to the infection, which could induce immune impairment in the brain. Therefore, this study highlights the importance of the neurotropic ability of $\mathrm{CoV}$ and its involvement in the CNS, especially in children who need more attention to control this serious viral infection.

\section{Acknowledgement}

The authors thank all family members for enrollment in this study. The authors appreciate the Department of Pediatrics of The First People's Hospital of Chenzhou for sample collection. This work was supported by The First People's Hospital of Chenzhou, University of South China (grant No: 2013-007, 2013-001, and 2014-003).

\section{Disclosure Statement}

All authors have no conflicts of interest regarding the work reported in this paper.

References

Intervirology 2016;59:163-169 DOI: $10.1159 / 000453066$
Li/Li/Fan/Wen/Zhang/Cao/Wang/Song/ $\mathrm{Li} / \mathrm{Li} / \mathrm{Lv} / \mathrm{Qu} / \mathrm{Huang} / \mathrm{Liu}$
1 Cabeca TK, Passos AM, Granato C, Bellei N: Human coronavirus ocurrence in different populations of Sao Paulo: a comprehensive nine-year study using a pancoronavirus RTPCR assay. Braz J Microbiol 2013;44:335-339.

2 Ren L, Gonzalez R, Xu J, Xiao Y, Li Y, Zhou H, Li J, Yang Q, Zhang J, Chen L, Wang W, Vernet G, Paranhos-Baccala G, Wang Z, Wang J: Prevalence of human coronaviruses in adults with acute respiratory tract infections in Beijing, China. J Med Virol 2011;83: 291-297. 
3 Birch CJ, Clothier HJ, Seccull A, Tran T, Catton MC, Lambert SB, Druce JD: Human coronavirus OC43 causes influenza-like illness in residents and staff of aged-care facilities in Melbourne, Australia. Epidemiol Infect 2005; 133:273-277.

4 Cabeca TK, Granato C, Bellei N: Epidemiological and clinical features of human coronavirus infections among different subsets of patients. Influenza Other Respir Viruses 2013; 7:1040-1047.

5 Gaunt ER, Hardie A, Claas EC, Simmonds P, Templeton KE: Epidemiology and clinical presentations of the four human coronaviruses 229E, HKU1, NL63, and OC43 detected over 3 years using a novel multiplex real-time PCR method. J Clin Microbiol 2010;48:29402947.

6 Shirato K, Yano T, Senba S, Akachi S, Kobayashi T, Nishinaka T, Notomi T, Matsuyama S: Detection of Middle East respiratory syndrome coronavirus using reverse transcription loop-mediated isothermal amplification (RT-LAMP). Virol J 2014;11:139.

7 Matoba Y, Abiko C, Ikeda T, Aoki Y, Suzuki Y, Yahagi K, Matsuzaki Y, Itagaki T, Katsushima F, Katsushima Y, Mizuta K: Detection of the human coronavirus 229E, HKU1, NL63, and OC43 between 2010 and 2013 in Yamagata, Japan. Jpn J Infect Dis 2015;68: 138-141.

8 Lau KK, Yu WC, Chu CM, Lau ST, Sheng B, Yuen KY: Possible central nervous system infection by SARS coronavirus. Emerg Infect Dis 2004; 10:342-344.

9 Arbour N, Day R, Newcombe J, Talbot PJ: Neuroinvasion by human respiratory coronaviruses. J Virol 2000;74:8913-8921.

10 Yeh EA, Collins A, Cohen ME, Duffner PK, Faden H: Detection of coronavirus in the central nervous system of a child with acute disseminated encephalomyelitis. Pediatrics 2004; 113:e73-e76.

11 Murray CJ, Lopez AD: Global mortality, disability, and the contribution of risk factors: global burden of disease study. Lancet 1997; 349:1436-1442

12 Tan le V, Thai le H, Phu NH, Nghia HD, Chuong LV, Sinh DX, Phong ND, Mai NT, Man DN, Hien VM, Vinh NT, Day J, Chau NV, Hien TT, Farrar J, de Jong MD, Thwaites G, van Doorn HR, Chau TT: Viral aetiology of central nervous system infections in adults admitted to a tertiary referral hospital in southern Vietnam over 12 years. PLoS Negl Trop Dis 2014;8:e3127.

13 Zhang Y, Li J, Zhan Y, Wu L, Yu X, Zhang W, Ye L, Xu S, Sun R, Wang Y, Lou J: Analysis of serum cytokines in patients with severe acute respiratory syndrome. Infect Immun 2004;72: 4410-4415.
14 Dodd DA, Giddings TH, Kirkegaard K: Poliovirus 3A protein limits interleukin-6 (IL-6), IL-8, and beta interferon secretion during viral infection. J Virol 2001;75:8158-8165.

15 Kaplanski G, Teysseire N, Farnarier C, Kaplanski S, Lissitzky JC, Durand JM, Soubeyrand J, Dinarello CA, Bongrand P: IL-6 and IL-8 production from cultured human endothelial cells stimulated by infection with Rickettsia conorii via a cell-associated IL-1 alphadependent pathway. J Clin Invest 1995;96: 2839-2844

16 Bell MD, Taub DD, Perry VH: Overriding the brain's intrinsic resistance to leukocyte recruitment with intraparenchymal injections of recombinant chemokines. Neuroscience 1996;74:283-292.

17 Wong CK, Lam CW, Wu AK, Ip WK, Lee NL, Chan IH, Lit LC, Hui DS, Chan MH, Chung SS, Sung JJ: Plasma inflammatory cytokines and chemokines in severe acute respiratory syndrome. Clin Exp Immunol 2004;136:95103.

18 Sheng WH, Chiang BL, Chang SC, Ho HN, Wang JT, Chen YC, Hsiao CH, Hseuh PR, Chie WC, Yang PC: Clinical manifestations and inflammatory cytokine responses in patients with severe acute respiratory syndrome. J Formos Med Assoc 2005; 104:715-723.

19 Yu D, Zhu H, Liu Y, Cao J, Zhang X: Regulation of proinflammatory cytokine expression in primary mouse astrocytes by coronavirus infection. J Virol 2009;83:12204-12214.

20 Gregory AD, Hogue LA, Ferkol TW, Link DC: Regulation of systemic and local neutrophil responses by G-CSF during pulmonary pseudomonas aeruginosa infection. Blood 2007; 109:3235-3243.

21 Eyles JL, Hickey MJ, Norman MU, Croker BA, Roberts AW, Drake SF, James WG, Metcalf D, Campbell IK, Wicks IP: A key role for G-CSF-induced neutrophil production and trafficking during inflammatory arthritis. Blood 2008;112:5193-5201.

22 Brand HK, Ferwerda G, Preijers F, de Groot R, Neeleman C, Staal FJ, Warris A, Hermans PW: CD4+ T-cell counts and interleukin-8 and CCL-5 plasma concentrations discriminate disease severity in children with RSV infection. Pediatr Res 2013;73:187-193.

23 Shiomi A, Usui T: Pivotal roles of GM-CSF in autoimmunity and inflammation. Mediators Inflamm 2015;2015:568543.

24 Croxford AL, Spath S, Becher B: GM-CSF in neuroinflammation: licensing myeloid cells for tissue damage. Trends Immunol 2015;36: 651-662.

25 Yavarian J, Gavvami N, Mamishi S: Detection of human herpesvirus 6 in cerebrospinal fluid of children with possible encephalitis. Jundishapur J Microbiol 2014;7:e11821.

26 Burgess AW, Camakaris J, Metcalf D: Purification and properties of colony-stimulating factor from mouse lung-conditioned medium. J Biol Chem 1977;252:1998-2003.
27 Hercus TR, Thomas D, Guthridge MA, Ekert PG, King-Scott J, Parker MW, Lopez AF: The granulocyte-macrophage colony-stimulating factor receptor: linking its structure to cell signaling and its role in disease. Blood 2009;114: 1289-1298.

28 Tsuboi K, Kimura T, Sugiura K, Hashimoto I, Nishikawa M, Uyama M, Fujisawa JI: Granulocyte-macrophage colony-stimulating factor expressed in $\mathrm{T}$ cells mediates immunity against herpes simplex virus type 1 encephalitis. J Infect Dis 1998;178:16-26.

29 Sakagami T, Uchida K, Suzuki T, Carey BC, Wood RE, Wert SE, Whitsett JA, Trapnell BC, Luisetti M: Human GM-CSF autoantibodies and reproduction of pulmonary alveolar proteinosis. N Engl J Med 2009;361:2679-2681.

30 Uchida K, Beck DC, Yamamoto T, Berclaz PY, Abe S, Staudt MK, Carey BC, Filippi MD, Wert SE, Denson LA, Puchalski JT, Hauck DM, Trapnell BC: GM-CSF autoantibodies and neutrophil dysfunction in pulmonary alveolar proteinosis. N Engl J Med 2007;356: 567-579.

31 van Strijp JA, van Kessel KP, Miltenburg LA, Fluit AC, Verhoef J: Attachment of human polymorphonuclear leukocytes to herpes simplex virus-infected fibroblasts mediated by antibody-independent complement activation. J Virol 1988;62:847-850.

32 Bingham EL, Fenger TW, Sugar A, Smith JW: Dependence on antibody for induction of chemiluminescence in polymorphonuclear leukocytes by herpes simplex virus. Invest Ophthalmol Vis Sci 1985;26:1236-1243.

33 Winter PM, Dung NM, Loan HT, Kneen R, Wills B, Thu le T, House D, White NJ, Farrar JJ, Hart CA, Solomon T: Proinflammatory cytokines and chemokines in humans with Japanese encephalitis. J Infect Dis 2004;190: 1618-1626.

34 Campbell IL, Stalder AK, Chiang CS, Bellinger R, Heyser CJ, Steffensen S, Masliah E, Powell HC, Gold LH, Henriksen SJ, Siggins GR: Transgenic models to assess the pathogenic actions of cytokines in the central nervous system. Mol Psychiatry 1997;2:125-129.

35 Kalita J, Srivastava R, Mishra MK, Basu A, Misra UK: Cytokines and chemokines in viral encephalitis: a clinicoradiological correlation. Neurosci Lett 2010;473:48-51.

36 Singh A, Kulshreshtha R, Mathur A: Secretion of the chemokine interleukin-8 during Japanese encephalitis virus infection. J Med Microbiol 2000;49:607-612.

37 D'Aversa TG, Weidenheim KM, Berman JW: CD40-CD40L interactions induce chemokine expression by human microglia: implications for human immunodeficiency virus encephalitis and multiple sclerosis. Am J Pathol 2002; 160:559-567. 